\title{
EXPERIMENTAL AND COMPUTATIONAL DESIGN AND TESTING OF A VALVE LESS PULSEJET ENGINE FOR THE APPLICATION OF MICRO AIR VEHICLE
}

\author{
Dr. SREENADH CHEVULA ${ }^{1}$, DHANA TEJA NALLIBOYANA ${ }^{2}$, Dr. A.P. HARAN ${ }^{3}$ \& SATYA PRASAD \\ MADDULA $^{4}$ \\ ${ }^{1,4}$ Department of Aerospace Engineering, GITAM (Deemed to be University), Rudraram Mandal, Hyderabad, Telangana, India \\ ${ }^{2}$ Department of Aeronautical Engineering, Mallareddy College of Engineering and Technology,
}

Secunderabad, Telangana, India

${ }^{3}$ Park Research Cell, Park College of Engineering and Technology, Kaniyur, Tamil Nadu, India

\begin{abstract}
Pulsejet engines are the different forms of jet propulsion engines (without rotary components) for air and ground vehicles. In the classification of the pulsejet engines, valveless pulse jet engines contain less weight and able to result in more thrust to weight ratio. Concerning the air and ground vehicle applications, valueless pulsejet engines are used in go-karts, UAVs, MAVs, missiles, and drones. In general, the Micro Air Vehicle designed with a small piston engine with propellers to obtain driving force. But this type of propeller engines has altitude limitations. To overcome these limitations, in the present paper, an attempt has been made to develop a scale down working model of valveless pulsejet engine, which can be used for an alternative solution for the propulsive applications of a Micro Air Vehicle (MAV). At the initial level of this work, the general geometrical and payload conditions of the MAV have been considered. The operational conditions of the MAV's will enable us to understand the required parameters such as flow field inside the combustion chamber and the required pressure rise within the combustor (to provide the necessary propulsive force). Finally, the work in this paper has been focused on the CFD analysis of the combustor of the valveless pulse jet engine. This work also aimed to design a prototype of a valveless pulse jet engine which can able to produce a propulsive force of 20 Newton's.
\end{abstract}

KEYWORDS: Pulse Jet Engine, Valve Less Pulsejet Engine, Micro Air Vehicle Thrust, CFD Analysis of Pulse Jet, Design of Micro Air Vehicle \& Design of Valve Less Pulsejet Engine

Received: Jul 24, 2019; Accepted: Aug 16, 2019; Published: Jul 30, 2020; Paper Id.: IJMPERDJUN2020536

\section{INTRODUCTION}

In general, jet engines like turbojet, turboprop, turbofan, and turboshaft engines contain many moving or rotary components which will gain the weight factor of entire air vehicles. As a result, more fuel will be consumed in the flying operations, which also increases the economical means. To overcome this problem, an alternative propulsive

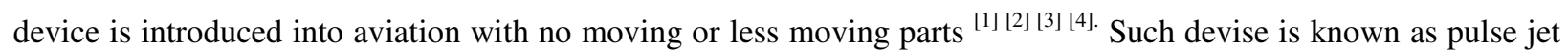
engines. Based on the design and operational requirements, the pulse jet engines have been classified into two types, namely, valved and valveless pulsejet engines. Firstly, in a valved pulsejet engine, a mechanical valve will be assembled in front of the combustion chamber to control the expansion of hot gases towards the intake of the engine and also force the same hot gas flow towards the tail part of the engine (to produce required thrust). Due to the arrangement of this mechanical valve and the vacuum created by the fuel-air mixture exploration in the combustion chamber, a very good possibility to obtain the rich air-fuel mixture at the intake area. In the design of the valved 
pulse jet engine mostly, daisy value and rectangular valve grid are widely used by the designers ${ }^{[4]}$. The presence of these mechanical valve mechanisms in a valved pulsejet engine, there is a possibility of popping up the "unexpected interruptions in the jet pulses" and "less efficiency of the engine".

To overcome the interruptions in jet pulses, and less engine efficiency, in the present work, designing of a vale less pulsejet engine (which is the second type of pulse jet engine) has been chosen. In most of the reaction engines, the thrust force has been obtained by the high internal pressure generated in the combustion chambers ${ }^{[5]}$. But the working principle of the valveless pulsejet engines is based on the alternation of pressure without using any mechanical values or devices. Considering the design of valveless pulsejet engines, it is a simple tubular structure that can obtain natural acoustic resonance. In both types (Valved and Vale less) of engines, the exhaust hot gases (Hot jet streams) are generated by the expansion waves, caused by the explosion of the fuel-air mixture in the combustion chamber ${ }^{[3]}$.

\section{THERMODYNAMICS OF PULSEJET ENGINE}

The pulse-jet engine is an internal combustion engine without any mechanical compression process in the design or operational levels. As a result of no compression process, pulse jet engines will obtain very low thermal efficiencies compare to other cycles such as Otto and Diesel cycle. Below Lenoir Cycle and Humphrey Cycle can explain the functioning of the pulse jet engines ${ }^{[5]}$
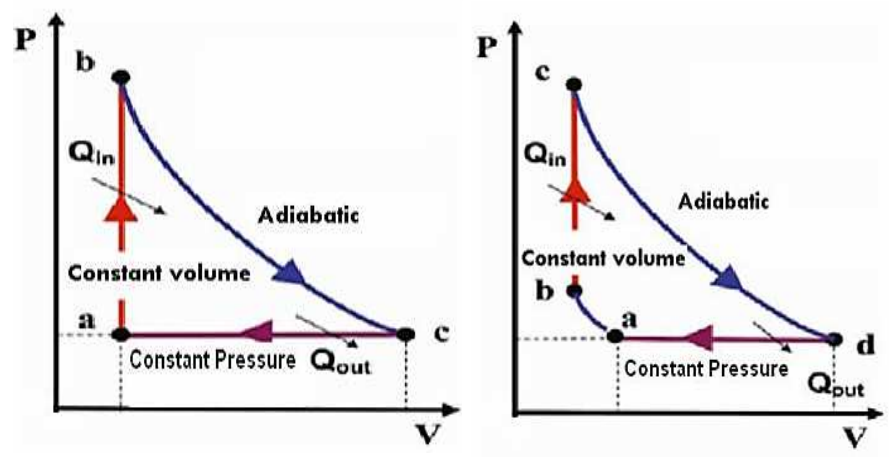

$\mathrm{c}$ to a - constant pressure compression

$\mathrm{a}$ to $\mathrm{b}$ - constant volume heat addition

$\mathrm{b}$ to $\mathrm{c}$ - adiabatic expansion $\mathrm{d}$ to $\mathrm{b}$ - constant pressure compression (with isentropic compression) $\mathrm{b}$ to $\mathrm{c}$ - constant volume heat addition(with isentropic compression) $\mathrm{c}$ to $\mathrm{d}$ - adiabatic expansion (with isentropic compression)

Figure 1: Lenoir Cycle of Pulsejet Engine ${ }^{[5]}$

Figure 2: Humphrey Cycle for Pulsejet Engine ${ }^{[5]}$

With respect to the thermodynamic analysis of pulsejet engine, isentropic expansion can be obtained by the compression from free stream to the stagnation pressure so that the combustor (hot air gas chamber) is at stagnation condition and the exit flow condition is a free stream condition, i.e,

$$
\frac{P_{1}}{P_{0}}=\left(1+\frac{\gamma-1}{2} M_{0}^{2}\right)^{\frac{\gamma}{\gamma-1}}
$$

In terms of temperature

$$
\frac{T_{1}}{T_{0}}=\left(1+\frac{\gamma-1}{2} M_{0}^{2}\right)
$$

At the opening of the valve, the velocity of the air towards the combustion chamber is at nearly sonic speed, i.e the 
pressure at inlet throat $P_{2}$ will approximately be,

$$
P_{2}=\frac{1}{2} P_{1}
$$

and the shape of the diffuser can help to obtain a small amount of kinetic energy in the form of a pressure energy.

If $T_{1}$ and $T_{2}$ are assumed as a temperatures of the and initial stage and hot stages of gas, and $T_{2}$ also denotes the total energy of the gas in rest stage, then there will be no heat losses take place i.e, $T_{2}=T_{1}(4)$

In the combustion process of the fuel air mixture at constant volume condition, the added heat $(h)$ will be

$$
h=C_{v}^{\prime}\left(T_{3}-T_{2}\right)=\frac{1}{\gamma^{\prime}} C_{p}^{\prime} T_{3}\left(1-\frac{T_{2}}{T_{3}}\right)
$$

In Equation (5) the prime quantities are nothing but combustion products at constant volume cycle then,

$$
\frac{T_{2}}{T_{3}}=\frac{P_{2}}{P_{3}}
$$

From Equation (5) and (6) $h=\frac{1}{\gamma} C_{p}^{\prime} T_{3}\left(1-\frac{P_{2}}{P_{3}}\right)$

The discharging of the hot air gas can be calculated based on the assumptions of isotropic steady expansions between the combustion chamber pressures $P$ to atmospheric chamber pressure $P_{0}$. In the creation of the pulsed thrust, the air fuel explosion in the combustion chamber will remove the mass in the chamber, which is also leads a drop in the chamber pressure. If there is no heat losses towards the atmosphere, the expansion of the gases in the combustion chamber is consider as isentropic.

The total impulse of the pulses can be calculated based on the slow discharge (due to the large combustion chamber and very small discharge nozzle design of pulsejet engine) instead of a rapid discharge. Assume that $v$ is the discharge velocity with respective to $P$ then

$$
v=-\sqrt{\left(\frac{2 \gamma}{\gamma^{\prime}-1}\right) \frac{P}{\rho}\left[1-\left(\frac{P_{0}}{P}\right)^{\frac{\gamma-1}{\gamma}}\right]}
$$

From Equation (8), the impulse caused by the discharge $d m$ will be $d I=v d m$

Where $m$ is the mass (before the removal of $d m$ )

The density and pressure ratios of chamber (before and after removal of $d m$ ) will be $\frac{m-d m}{m}$ and $\frac{P+d P}{P}$ respectively, and the combustion process in the chamber is isotropic then $\frac{P+d P}{P}=\left(\frac{m-d m}{m}\right)^{\gamma}$. If we neglecting high order terms then

$$
\gamma \frac{d m}{m}=-\frac{d P}{P}
$$


From Equation (10), it can be observed that the discharge $d m$ is the cause for the reduction in the chamber pressure. As well-known equation for the mass of gas inside the chamber is $m=\rho \mathrm{V}$

Where $V$ is the volume of the combustion chamber. From Equation (11) introduce the $d m$ value in Equation (9) to obtain value of $d I$ thus,

$$
d I=\sqrt{\frac{(2 \gamma) P}{(\gamma-1) \rho}\left[1-\left(\frac{P_{0}}{P}\right)^{\frac{\gamma-1}{\gamma}}\right]} \frac{1}{\gamma} \rho V \frac{d P}{P}
$$

From Equation (12) it can be observed that, the total impulse based on the discharge can be obtained by the integration with the range of pressure variations $\mathrm{P}_{3}$ to $\mathrm{P}_{0}$.

$$
I=\frac{1}{\gamma^{\prime}} \sqrt{\frac{\left(2 \gamma^{\prime}\right)}{\left(\gamma^{\prime}-1\right)}}\left(V \rho_{3}\right) \sqrt{\frac{P_{3}}{\rho_{3}}} \int_{\frac{P_{0}}{P_{3}}}^{1} \sqrt{\frac{1}{\eta^{\frac{\gamma^{\prime}-1}{\gamma}}\left[1-\left(\frac{P_{0}}{P_{3}}\right)^{\frac{\gamma^{\prime}-1}{\gamma}} \frac{1}{\eta^{\frac{\gamma^{\prime}-1}{\gamma}}}\right]}} d \eta
$$

Where $\eta=\frac{P}{P_{3}}$. But $\mathrm{VP}_{3}$ is the total mass in the combustion chamber. $\sqrt{\left(\gamma \frac{P_{3}}{\rho_{3}}\right)}$ is the velocit of the sound $\mathrm{a}_{3}$.

The effective exit velocity $V_{e}$ can be calculated based on

$$
\frac{V_{e}}{a_{3}}=\frac{1}{\gamma} \sqrt{\frac{(2)}{\left(\gamma^{\prime}-1\right)}} \int_{\frac{P_{0}}{P_{3}}}^{1} \sqrt{\frac{1}{\eta^{\frac{\gamma-1}{\gamma}}}\left[1-\left(\frac{P_{0}}{P_{3}}\right)^{\frac{\gamma^{\prime}-1}{\gamma}} \frac{1}{\eta^{\frac{\gamma-1}{\gamma}}}\right]} \mathrm{d}
$$

Assume that $V_{e}$ and $V_{0}$ are the exit and flight velocities of the gases in the combustion chamber, then the average thrust force is $1 V_{e}$ for an average mass flow rate of one unit per second and $\mathrm{H}$ is heat value for one $\mathrm{lb}$ and $\eta_{b}$ is the combustion chamber efficiency, then the specific fuel consumption $I_{s p} / \mathrm{hr}$ thrust is

$$
I_{S P}=\frac{3600 h}{778 H \eta_{b}\left(V_{e}-V_{0}\right)}
$$

From Equation (7) the value of $h$ can be introduced in Equation (15) then

$$
\begin{gathered}
I_{S P}=\frac{3600 a_{3}\left(1-\frac{P_{2}}{P_{3}}\right)}{778 H \eta_{b}\left[\frac{V_{e}}{a_{3}}-M_{0}\left(\frac{a_{0}}{a_{3}}\right)\right]} \frac{1}{\gamma^{\prime}\left(\gamma^{\prime}-1\right)} \\
\left(\frac{a_{3}}{a_{0}}\right)^{2}=\frac{\gamma^{\prime} R^{\prime} T_{3}}{\gamma^{\prime} R^{\prime} T_{0}}=\frac{C_{p}^{\prime} \gamma^{\prime}-1}{C_{p} \gamma-1}\left(\frac{P_{3}}{P_{2}}\right)\left(\frac{T_{1}}{T_{0}}\right)
\end{gathered}
$$

From Equations (16) and (17) it can be observed that based on the obtained experimental values of $\frac{P_{2}}{P_{3}}$ and $\eta_{b}$ the specific fuel consumption $I_{s p}$ can be calculated. 


\section{THRUST GENERATION}

In a valueless pulsejet engine, instead of a mechanical valve, the intake air at the throat of the combustion chamber is going to act as a mechanical valve. The basic principle of this invisible value depends on the pressure difference that occurred raised between the gas moments from the intake to the combustion chamber and outwards from the combustion chamber to the nozzle. A small delay in the combustion process will be seen due to the presence of invisible air vale at the throat of the combustion chamber. As a result, instead of continuous thrust, Pulse of thrust will be obtained over a significant fraction of the cycle time. In general, the design of a valveless pulsejet engine contains very small dimensions of the intake duct which will cause the intake mass of the air will be in very small fractions in the comparison of air mass flow in the tailpipe. The carefully designed imbalance of these two air masses will play a major role in the thrust generation cycle and avoid the failures of the engine design.

At the starting of the combustion process, a significantly raised pressure moves towards the nozzle through both air masses as a compression wave with a sonic speed that moves in both directions of intake and tailpipe. Whenever the pressure waves reach the inlet side, a low atmospheric rarefaction pressure wave pushes back in the reverse direction i.e, reflected by the open end will occur. The combustion cycle and the creation of the thrust can be explained by the internal mechanism of the Kadenacy effect i.e, until the arrival of the rarefaction wave, there will be no fresh air that will be entered into the combustion chamber ${ }^{[7]}$.

The pressure waves generated due to the starting of the combustion process will move through both air and masses and the hot gases are going to be at the beginning of the combustion chamber. Behind the pressure wave, the intake air will be accelerated towards the nozzle direction and at the tailpipe, the discharge of air mass will be very slow. It can also be observed that the eventual flow reversal will take place much sooner in the intake, due to its smaller air mass. The calculation of the wave motions timings depends on the length, and volume of the intake, and main tube of the engine. The influence of the local gas temperatures also considers in these calculations.

\section{DESIGN OF VALVELESS PULSEJET ENGINE}

As specified for proposed MAV thrust requirements, the design specifications of valve less pulse jet engine are calculated and the values are ${ }^{[6]}$;Air mass flow rate $=0.59 \mathrm{~kg} / \mathrm{s}$ at entry Mach number of 0.1 ; Fuel (LPG) flow rate $=0.0343 \mathrm{~kg} / \mathrm{s}$ Equivalence ratio $=0.4$ to 1.0; Static thrust= 20-30N (Approx.);Nozzle Length $=400 \mathrm{~mm}$; Nozzle Mean Diameter $=100$ mm; Nozzle Length/Nozzle Mean Diameter $=4$; Combustion Chamber Length $=355 \mathrm{~mm}$; Chamber Mean Diameter $=$ 237mm; Chamber length/Chamber Mean Diameter $=1.49$; Tail Pipe Length $=2500 \mathrm{~mm}$; Tail Pipe Mean Diameter $=$ 92.3mm; Tail Pipe Length/Tail Pipe Mean Diameter = 27; 


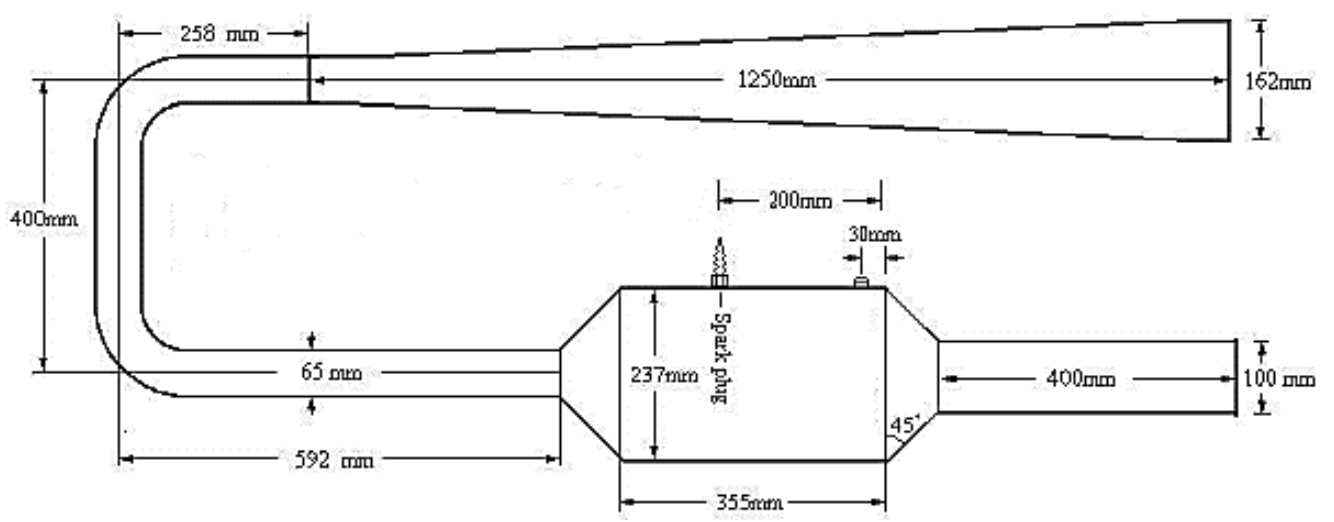

Figure 3: Schematic Diagram of the Valve less Pulsejet Engine ${ }^{[8]}$.

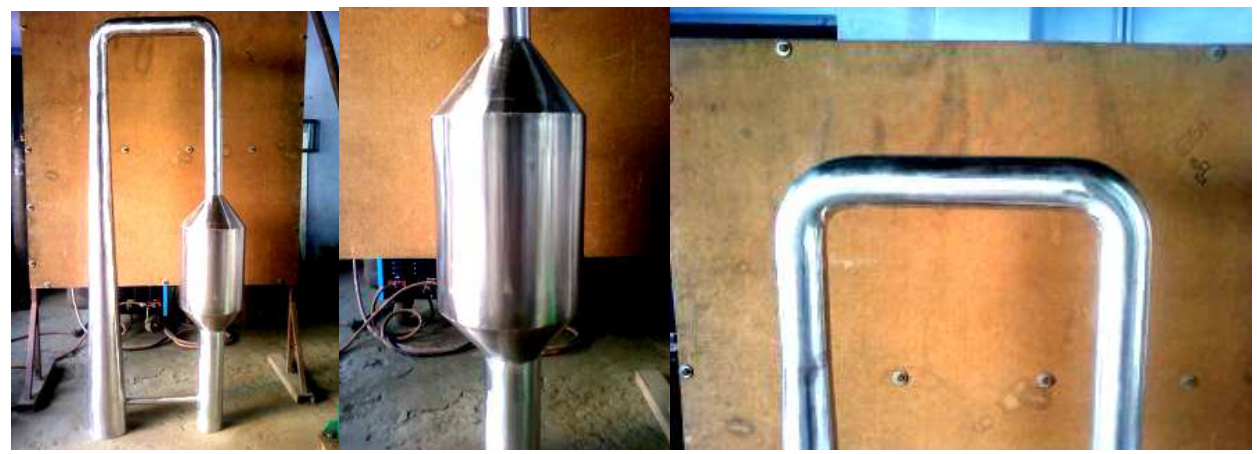

Valve less Pulsejet Engine Combustion Chamber Intake at the right to the exhaust at left

Figure 4: Valve less Pulsejet Engine after fabrication [8].

\section{CFD STUDIES / ANALYSIS}

Computational studies of the flow field are required to determine the pressure rise during combustion and the frequency of the combustion process. In this line, the same studies are carried out to identify the fuel injection point and the spark plug location on the combustion chamber. For a smooth initialization and stabilization of flame in the combustion chamber, identifications of the accurate locations of fuel injection point and the spark plug location will help in the engine setup. The following figs show the results of the studies carried out in FLUENT.

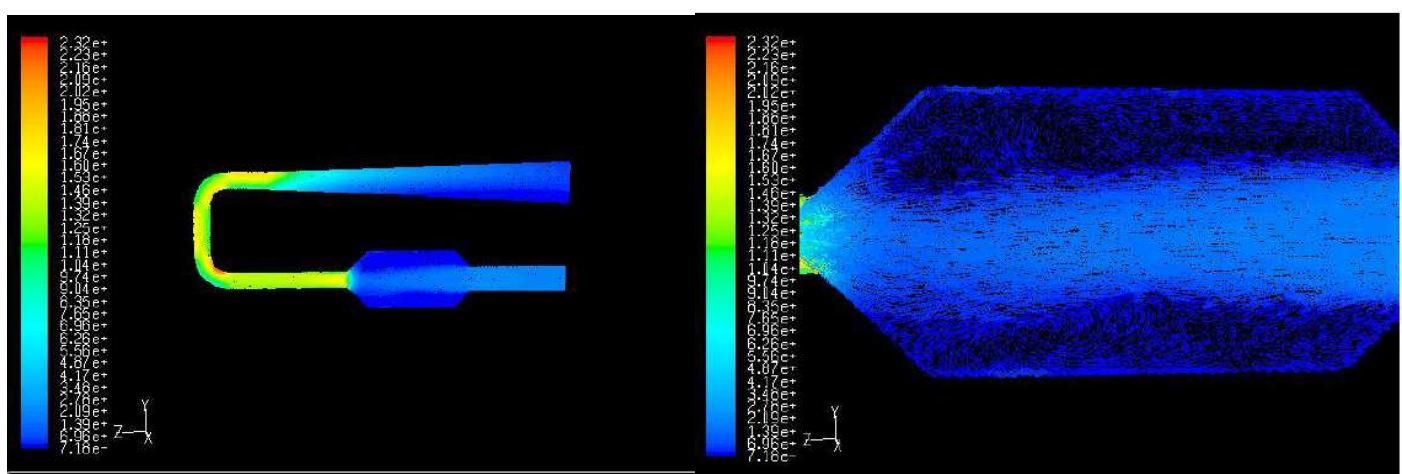

Figure5: Dynamic Pressure Study in Figure6: Dynamic Pressure Study in Valve less Pulsejet Body Combustion 


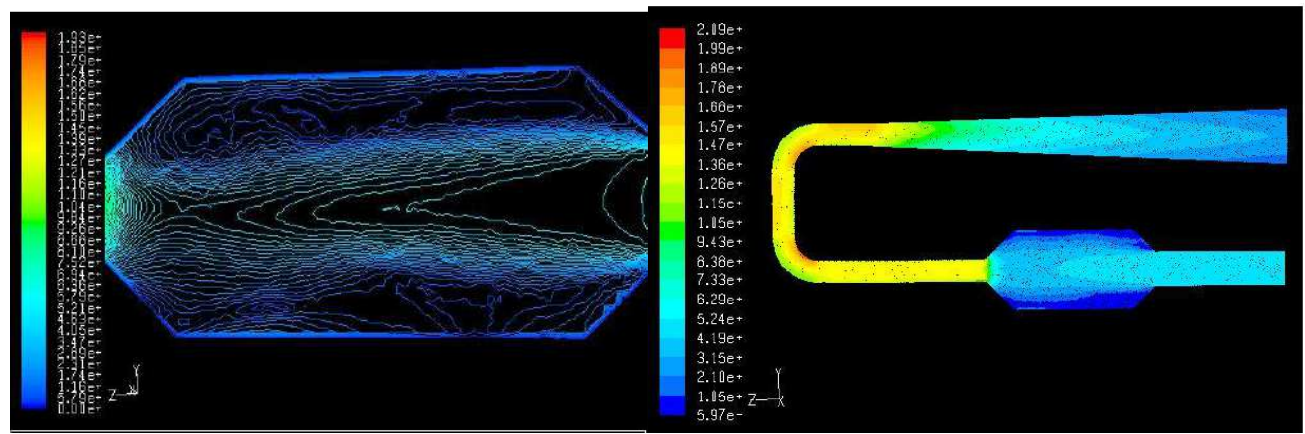

Figure7: Study of Velocity Magnitudes in Figure8: Study of Velocity Magnitudes in Combustion Chamber pulsejet body

From the results obtained by the CFD analysis, it has been found that a spark plug is need to be employed (for ignition purpose) at a distance of $170 \mathrm{~mm}$ from the inlet hole. As a next step of the implementation, an electrical circuit has been designed for getting at least 2 sparks per second as shown in fig 16.

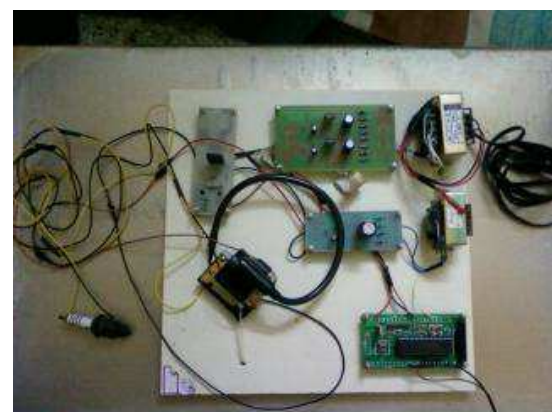

Figure 9: Circuit Board with spark plug at left

The typical elements of this circuit board are Transformer, ignition coil, MOSFET (Metal Oxide Semiconductor Field Effect Transistor), MOSFET Driver. In MOSFETs, a voltage on the oxide-insulated gate electrode can induce a conducting channel between the two other contacts called source and drain. So it is used to create pulses. It produces around 3-5 pulses per second. As the name suggests the MOSFET Driver is used to drive the MOSFET. The Transformer used here is used to step up the voltage from $20 \mathrm{~V}$ to $20 \mathrm{KV}$. Regarding the ignition coil, first it was decided to use electronic Ignition coil. But then it was settled to use Automobile ignition coil (2 Wheelers).

\section{EXPERIMENTAL VALIDATIONS}

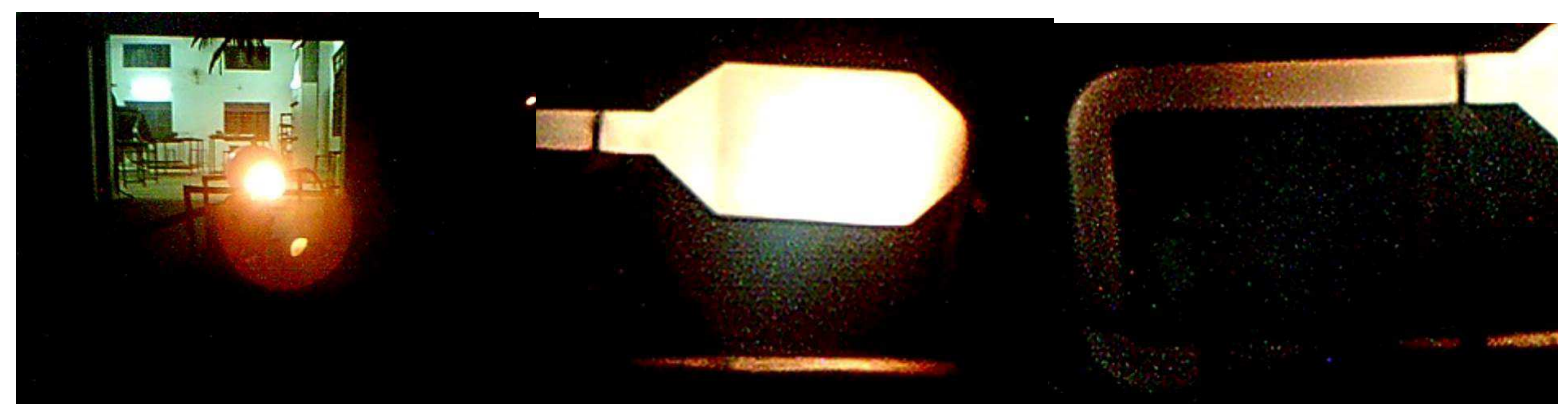

Figure 10: This is the view towards. Figure 11. The combustion is spreading Figure 12. Here the bend pipe has the inlet combustion is starting. towards the bend pipe (red hot also reached red hot condition. so the combustion to spread condition combustion) is now spreading towards the exhaust

Two injectors have been designed for injecting the fuel flow into the combustion chamber. First injector with one 
hole with $4 \mathrm{~mm}$ diameter and the second one with $2 \mathrm{~mm}$ diameter with four holes around the first hole for swirling action. Considering both the injectors, calculations were done to find out at what pressure the pulsejet engine should be operated.

For 2 mm Injector

$$
\text { Area, } A=\frac{\pi}{4} d^{2}=3.14 \times 10^{-6} \mathrm{~mm}^{2}
$$

\section{For 4 mm Injector}

$$
\text { Area, } A=\frac{\pi}{4} d^{2} \quad=1.256 \times 10^{-5} \mathrm{~mm}^{2}
$$

For back pressures ranging from 1 bar to 4 bar, the mass flow rate is

$$
\frac{m}{A}=\frac{\sqrt{2 \times \gamma\left(p_{0}\right)\left\{1-\left(\frac{p_{a}}{p_{0}}\right)^{\frac{\gamma-1}{\gamma}}\right\}\left(\frac{p_{a}}{p_{0}}\right)^{\frac{1}{\gamma}}}}{\gamma-1\left(R T_{0}\right)}
$$

Where $P_{a}=1$ bar, $T_{0}=293 \mathrm{~K}, \mathrm{R}=287 \mathrm{j} / \mathrm{kg}-\mathrm{k}, \gamma=1.4$

$$
\frac{m}{A} \times \sqrt{\frac{T_{0}}{P_{0}}}
$$

\begin{tabular}{|c|c|c|c|c|c|c|c|c|c|c|}
\hline $\begin{array}{c}\text { Table 1: For } \\
\text { 4 mm injector }\end{array}$ & & \multicolumn{2}{|c|}{$\begin{array}{c}\text { Table 2: for 2 mm } \\
\text { injector }\end{array}$} & \multicolumn{2}{|c|}{$\begin{array}{c}\text { Table 3: Data for 4 mm } \\
\text { injector }\end{array}$} & \multicolumn{2}{c|}{$\begin{array}{c}\text { Table 4: Data for 2 mm } \\
\text { injector }\end{array}$} \\
\hline$\frac{m}{A} \times \sqrt{\frac{T_{0}}{P_{0}}}$ & $\frac{P_{b}}{P_{0}}$ & & $\frac{m}{A} \times \sqrt{\frac{T_{0}}{P_{0}}}$ & $\frac{P_{b}}{P_{0}}$ & $P(b a r)$ & $m(k g / s)$ & & $P(b a r)$ & $m(k g / s)$ \\
\hline 0.00017 & 1 & & 0.00017 & 1 & 1 & 0.00058 & 1 & 0.00012 \\
\hline 0.0386 & 0.6666 & 0.0385 & 0.66 & 1.5 & 0.0004 & 1.5 & 0.00019 \\
\hline 0.0403 & 0.5 & & 0.0403 & 0.5 & 2 & 0.00081 & & 0.00018 \\
\hline 0.0389 & 0.4 & & 0.0388 & 0.4 & 2.5 & 0.00093 & 2.5 & 0.00021 \\
\hline 0.0369 & 0.333 & 0.03688 & 0.33 & 3 & 3 & 0.00105 & & 3 & 0.00024 \\
\hline
\end{tabular}

From Table 1 and Table 2 it has been observed that, for the both $2 \mathrm{~mm}$ and $4 \mathrm{~mm}$ injectors, obtained mass flow rates are similar.It also has been observed that after $P_{b} / P_{0}=0.5$ i.e., when $P_{0}=2$ bar, the value starts decreasing. Similarly, with different pressure values, the mass flow rate values have been calculated.From Table 3 and Table 4 it has been observed that the $4 \mathrm{~mm}$ injector at 1.5 bar of pressure, mass flow rate decreases and then starts increasing at 2 bar pressure. For $2 \mathrm{~mm}$ injector, at 2 bar mass flow decreases and then it starts increasing for other pressure values. Based on this conclusions, it has been decided to operate the fuel flow at a pressure range around 1.5 bar. At later stages in the experimental investigation, it has been observed that $4 \mathrm{~mm}$ injector resulted more combustion rate than $2 \mathrm{~mm}$ injector with swirling action.

\section{CONCLUSIONS}

From the proposed experimental setup and designed valve less pulse jet engine, obtained thrust force was nearly 15.5 to 
20 Newton's at the condition of fuel flow at pressure range around 1.5 to 2 bar. Total combustion has been taken place inside the designed combustion chamber without any mechanical valve integration. We found the expanded hot gas exhaust at other end of the designed engine. A constant pulses have been observed in the thrust production cycle. Considering the position and fuel injector area, $4 \mathrm{~mm}$ injector at 1.5 bar of pressure, mass flow rate decreases and then starts increasing at 2 bar pressure. For $2 \mathrm{~mm}$ injector, at 2 bar mass flow decreases and then it starts increasing for other pressure values,So the designed engine has an optimal stage when the fuel flow at an incoming flow's pressure range around 1.5 bar. Finally, a further studies and implementations for the designed value less pulsejet engine are proposed to obtain the aim of this paper.

\section{REFERENCES}

1. "Pulse Detonation Engine". Gofurther.utsi.edu. Archived from the original on 4 September 2014. Retrieved 3 March 2014.

2. https://news.google.com/patents/about?id=vOZsAAAAEBAJ. Retrieved 23 February 2016. Missing or empty |title= (help)[dead link]

3. "Patent US6216446 - Valve less pulse-jet engine with forward facing intake duct - Google Patents". Google.com. Retrieved 2014-03-03.

4. "Valve less Pulsejet". Home.no. Retrieved 2014-03-03.

5. https://core.ac.uk/download/pdf/71674951.pdf

6. Karthick Raja.R et al., "Design and Optimization of Valve less Pulsejet Engine” Journal of Engineering Research and Applications, Vol. 4, Issue 11(Version - 5), November 2014, pp.56-59.

7. Cory Kerr., James Reynolds., "Valueless Pulsejet Engine” BSc Thesis, California Polytechnic State University, San Luis Obispo.

8. Valve less pulsejet engine testing facility, Park research cell, Coimbatore. 

